\title{
BMJ Open Quality Reaching the summit of discharge summaries: a quality improvement project
}

Richard Thomas Richmond (D) , ${ }^{1}$ Isobel Joy McFadzean (D) ,2 Pramodh Vallabhaneni (D) ${ }^{1}$

To cite: Richmond RT, McFadzean IJ, Vallabhaneni P. Reaching the summit of discharge summaries: a quality improvement project. BMJ Open Quality 2021;10:e001142. doi:10.1136/ bmjoq-2020-001142

Received 14 August 2020 Revised 21 January 2021 Accepted 27 January 2021
Check for updates

(c) Author(s) (or their employer(s)) 2021. Re-use permitted under CC BY-NC. No commercial re-use. See rights and permissions. Published by BMJ.

${ }^{1}$ Paediatrics, Swansea Bay University Health Board, Port Talbot, UK

${ }^{2}$ Swansea Bay University Health Board, Port Talbot, UK

Correspondence to Dr Pramodh Vallabhaneni; pramodh.vallabhaneni@wales. nhs.uk

\section{ABSTRACT}

Background Discharge summaries need to be completed in a timely manner, to improve communication between primary and secondary care, and evidence suggests that delays in discharge summary completion can lead to patient harm.

Following a hospital health and safety review due to the sheer backlog of notes in the doctor's room and wards, urgent action had to be undertaken to improve the discharge summary completion process at our hospital's paediatric assessment unit. It was felt that the process would best be carried out within a quality improvement (QI) project.

Methods Kotter's 'eight-step model for change' was implemented in this QI project with the aim to clear the existing backlog of pending discharge summaries and improve the timeliness of discharge summary completion from the hospital's paediatric assessment unit. A minimum target of $10 \%$ improvement in the completion rate of discharge summaries was set as the primary goal of the project.

Results Following the implementation of the QI processes, we were able to clear the backlog of discharge summaries within 9 months. We improved completion within 24 hours, from $<10 \%$ to $84 \%$, within 2 months. The success of our project lies in the sustainability of the change process; to date we have consistently achieved the target completion rates since the inception of the project. As a result of the project, we were able to modify the junior doctor rota to remove discharge summary duty slots and bolster workforce on the shop floor. This is still evident in November 2020, with consistently improved discharge summary rates.

Conclusion QI projects when conducted successfully can be used to improve patient care, as well as reduce administrative burden on junior doctors. Our QI project is an example of how Kotter's eight-step model for change can be applied to clinical practice.

\section{PROBLEM DESCRIPTION}

The project was identified in June 2016 at a district general hospital in Wales. Our paediatric assessment unit (PAU) sees 5800-6200 admissions in a typical year, with each admission requiring a discharge summary. On particularly busy days, around 50 children/ young people can be assessed in a 24-hour period.
Due to the number of admissions and staffing issues (lack of engagement with summaries and lack of training on the information technology (IT) system), there was a historical backlog of discharge summaries, leading to problems such as poor communication with other colleagues especially those in primary care, as well as missed outpatient appointments for the patients. The unit often received phone calls from general practitioners, who required information that should have been delivered within a discharge summary.

To worsen the situation, a backlog of discharge summaries (figure 1) had developed following the introduction of standardised electronic discharge summary with mandatory fields required for completion. This large volume of notes led to a health and safety assessment for the paediatric unit, and an urgent recommendation was issued to protect staff from risk of injury. There are no financial penalties to such an act within Wales, but this was thought to not be best practice.

The rationale for the project came from the Professional Record Standards Body's eDischarge summary guidance, which states that an electronic discharge summary should be sent to the patient's primary care provider within 24 hours of discharge from unscheduled care. ${ }^{1}$ This guideline is endorsed by the Royal College of Paediatrics and Child Health (RCPCH).

Our initial aim was to clear the preexisting backlog of notes awaiting a discharge summary completion. The secondary aim of the project was to achieve a $10 \%$ monthly incremental rate improvement in discharge summary completion rates within 24 hours of discharge. The eventual goal of this ongoing quality improvement (QI) project would be to achieve $100 \%$ of discharge summaries completed within 24 hours of patient discharge. 


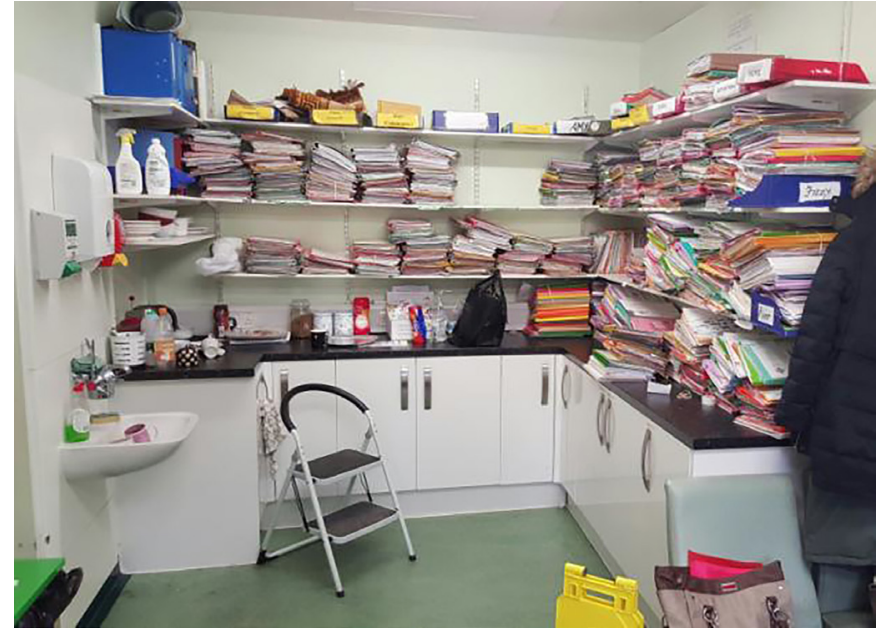

Figure 1 Pending discharge summaries at the start of the project.

\section{BACKGROUND TO THE PROJECT}

In addition to the standards set by RCPCH, a recent systematic review and meta-analysis by Schwarz et $a l^{2}$ suggested that delayed discharge summaries may lead to a lack of continuity of care, resulting in reduced satisfaction for both patients and general practitioners. Were $e t$ $a \hat{l}$ found that delayed completion of discharge summaries contributed to readmission rates, a similar conclusion was reached by Hoyer et al. ${ }^{4}$ Arjunan $^{5}$ has shown how Plan, Do, Study, Act (PDSA) cycles can be used to improve completion rates by allocating discharge summary 'Champions'. Cook et at formally reviewed the completeness of discharge summaries in their department on a monthly basis and improved the quality of their discharge summaries by feeding back to individual team members where necessary.

Moy et $a l^{7}$ among others, have shown that standardised electronic discharge summaries with mandatory fields result in improved satisfaction from general practitioners in comparison with free-text discharge summaries. This is because they are less likely to omit important information that general practitioners need to be aware of, such as changes to a patient's regular medication. This was the rationale for continuing to use the electronic format for our discharge summaries.

To our knowledge, this is the first QI project that documents the use of Kotter's eight-step model for instigating change to improve discharge summary completion rates.

\section{OUTCOME MEASURES}

There were three outcome measures used in the QI project:

1. The total proportion of generated discharge summaries completed each month.

2. The proportion of generated discharge summaries that were completed within 5 days of patients being discharged.

3. The proportion of generated discharge summaries completed within 24 hours of patient discharge.

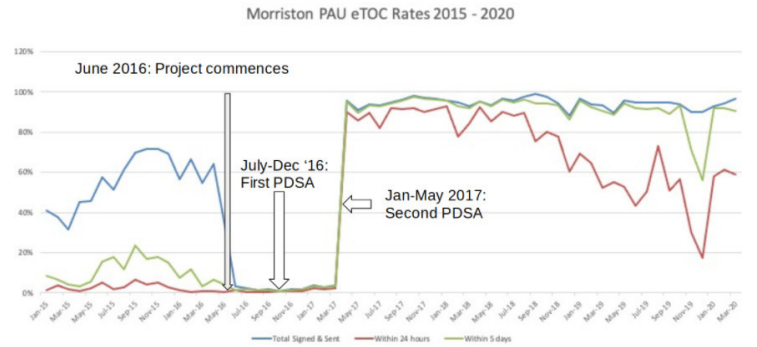

Figure 2 A run chart to show the proportion of generated discharge summaries completed monthly from January 2015 to March 2020. The project commenced in June 2016. PAU, paediatric assessment unit; PDSA, Plan, Do, Study, Act.

Discharge summary 'completion' was defined as electronic 'signing off' of the discharge summary, that is, the point at which the discharge summaries were sent electronically to the general practice. We were particularly interested in improving the proportion of discharge summaries completed within 24 hours of patient discharge as this is the RCPCH standard.

\section{BASELINE PERFORMANCE}

With help from the hospital's informatics and medical records departments, we were able to retrospectively assess our monthly discharge summary completion rates over the previous 18 months, in order to obtain a realistic picture of our previous performance. In the 18 months prior to the project commencing, fewer than $7 \%$ of discharge summaries had been completed within 24 hours of the patient discharge on any given month. The 'best' performance of the department in the preceding 2 years was a completion rate of $6.5 \%$ of discharge summaries within 24 hours of discharge (in September 2015) and the worst was $0.2 \%$, (May 2016) as shown in figure 2.

\section{PROJECT DESIGN}

Professor John Kotter's eight-step model for change (table 1$)^{8}$ was initially developed in the world of business, but has since been used across many sectors to institute long-lasting changes in practice, including healthcare.

We wanted to observe if Kotter's model could be applied successfully in practice to clear the backlog of discharge summaries and if it could be used to improve the timeliness of discharge summary completion. We wanted to make the change sustainable, and so aimed only for $10 \%$ incremental improvements in discharge summary completion rates. Creating a sustainable change is a part of Kotter's eight-step model and we therefore addressed this within the project. The eight steps used to implement the QI project are described below.

\section{IMPLEMENTATION OF THE EIGHT-STEP MODEL \\ Step one}

The first step of Kotter's eight-step model is to create a sense of urgency. This was created following our department stocking a large backlog of patient notes requiring 


\begin{tabular}{ll}
\hline Table 1 Kotter's eight-step model for change \\
\hline Step of Kotter's model & Description \\
\hline One & $\begin{array}{l}\text { Create a sense of urgency for } \\
\text { change }\end{array}$ \\
Two & $\begin{array}{l}\text { Form a coalition of individuals } \\
\text { willing to help make the change }\end{array}$ \\
Three & $\begin{array}{l}\text { Create a vision for change } \\
\text { Four }\end{array}$ \\
Five & $\begin{array}{l}\text { Share the vision for change with } \\
\text { others }\end{array}$ \\
Six & $\begin{array}{l}\text { Empower people to remove } \\
\text { obstacles to change }\end{array}$ \\
Seven & $\begin{array}{l}\text { Create short-term wins } \\
\text { Consolidate and build on the } \\
\text { change }\end{array}$ \\
Eight & $\begin{array}{l}\text { Make the change become the new } \\
\text { norm }\end{array}$ \\
\hline
\end{tabular}

discharge summaries. We had to hasten this endeavour in view of complaints from general practitioners, due to poor timeliness on the completion of our discharge summaries, and the advisory given as a result of the aforementioned internal health and safety review.

A consultant-led multidisciplinary team meeting (composed of representatives from management, nursing, ward clerks and junior doctors) helped to create a sense of urgency and commence the second step of the model for change. There are many general practitioner trainees who work within this paediatric department, and they helped to aid in the discussion about what is usually required within a summary for the colleagues within primary care.

\section{Step two}

The second step of Kotter's model is to build a guiding coalition. Our project's coalition comprised of a volunteer group of doctors, nurses, ward clerks, members of the hospital's IT and management team. Doctors of all grades from foundation trainees to consultants agreed to contribute to the project. Proactive doctors volunteered to become discharge summary champions, who agreed to make special effort to complete discharge summaries in a timely manner and encourage others to do the same. Consultants agreed to remind junior doctors to complete discharge summaries and members of the nursing team volunteered to inform doctors that patients were not to be discharged without a discharge summary. Ward clerks agreed to present doctors with discharge summaries that required completion. Having commenced all these measures, a coalition was created to ensure the success of the project.

\section{Steps three and four}

The third and fourth steps of Kotter's model is to create a vision for change and to communicate this vision. Our vision for change was to clear the backlog of discharge summaries and then to improve discharge summary completion rates in $10 \%$ incremental targets with the eventual aim that $100 \%$ of generated discharge summaries were completed within 24 hours. This vision was communicated via multiple conduits including face to face, email and posters. The coalition's vision was also promoted opportunistically and at regular events such as at daily team handovers.

\section{Step five}

The fifth step in the model for change involves identifying and removing barriers to facilitate change. We asked members of the coalition to identify institutional barriers to completing discharge summaries within 24 hours of patient discharge.

It was evident from the initial meeting of the coalition that some doctors working in the department were not familiar with using the new electronic discharge summary system. This problem became the basis of our first PDSA cycle (table 2).

In the interim, since urgent action was required, it was suggested we revert back to our old handwritten paperbased discharge summaries until the backlog had been cleared. There were no objections to this idea from our coalition, in fact this proposal was popular with other members of our coalition such as ward clerks who were happy that action was being taken to try and ameliorate the problem.

Our first PDSA cycle aimed to ensure that doctors working in our department became familiar with the new electronic discharge summary software while we were still using the interim paper-based discharge summary system. We aimed to ensure that at least $80 \%$ of doctors in our department completed the training within 3 months. We predicted that there would not be any significant change in electronic discharge summary completion rates until we stopped using the paperbased system. We realised the training would need to be offered on several occasions to ensure most doctors received the training.

We also encountered personal barriers to change from individuals who, for example, felt that it was not possible to make any meaningful change to our discharge summary completion rate and that previous attempts to improve our completion rates had not led to any sustained improvement. It was for this reason that we aimed for the smaller, more achievable $10 \%$ improvement rate per month (compared with baseline).

Blount and Carroll noted in Harvard Business Review ${ }^{9}$ that overcoming resistance requires at least two conversations with the persons who are resisting a proposed change. With this in mind, we held a meeting where we listened to and noted the concerns aired by the persons who thought that change was unfeasible. In the first meeting, we did not challenge the reasons given for resistance, nor did we offer potential solutions. It was only in a later meeting we tried to address the concerns aired specifically. 
Table 2 Our first PDSA cycle

\begin{tabular}{|c|c|c|c|}
\hline & What & Who & When \\
\hline Plan & $\begin{array}{l}\text { Evaluate all steps involved in completing discharge } \\
\text { summaries. Prepare a list of steps involved. } \\
\text { Arrange for doctors to receive training in use of } \\
\text { electronic discharge summary software while we are } \\
\text { still using paper-based summaries. }\end{array}$ & Project team & July 2016 \\
\hline Do & $\begin{array}{l}\text { Doctors receive the training delivered by the IT } \\
\text { department. } \\
\text { Work begins on clearing historical backlog. }\end{array}$ & $\begin{array}{l}\text { Doctors, IT } \\
\text { department }\end{array}$ & $\begin{array}{l}\text { Training sessions were held } \\
\text { between August and October 2016, } \\
\text { coinciding with new juniors joining the } \\
\text { department in August } 2016 \text {. }\end{array}$ \\
\hline Study & $\begin{array}{l}86 \% \text { of doctors working in the department received } \\
\text { the training. } \\
\text { Obtain feedback from doctors regarding the utility of } \\
\text { the training. } \\
\text { As expected, training does not increase completion } \\
\text { rates as we were still using an interim paper-based } \\
\text { system. } \\
\text { Identify further barriers to change with a second } \\
\text { coalition meeting - lack of computer terminals } \\
\text { identified as a barrier. }\end{array}$ & $\begin{array}{l}\text { Project team } \\
\text { and coalition }\end{array}$ & November 2016 \\
\hline Act & $\begin{array}{l}\text { Training was made a part of induction for new } \\
\text { doctors joining the department. } \\
\text { Clarify queries from coalition members. } \\
\text { Plan to obtain new computer terminals. }\end{array}$ & $\begin{array}{l}\text { Project team } \\
\text { and coalition }\end{array}$ & December 2016 \\
\hline
\end{tabular}

$\mathrm{IT}$, information technology.

\section{Step six}

The sixth step of Kotter's model involves celebrating early successes to maintain motivation for the change. Longterm engagement from team members requires motivation that enables persistence of changed behaviour. We held regular discharge summary completion parties to sustain momentum and achieve our initial goal of clearing the backlog, which took 9 months (June 2016March 2017). Junior members were thanked personally by senior team members to create a sense of a teambased effort to complete the discharge summaries, which was positively received, helping to break down personal barriers outlined in step five.

\section{Step seven}

Step seven involves building on the earlier successes of the project. Following the clearing of the backlog, we asked team members what was going well and how we could facilitate further improvement. Junior doctors in the department stated that there were not enough computers for more than a few of them to complete discharge summaries simultaneously. This fact was the basis of our second PDSA cycle in the QI project (table 3)

The aim of the second PDSA was to increase monthly discharge summary completion rates by $10 \%$ in the month that followed the change.

\begin{tabular}{|c|c|c|c|}
\hline & What & Who & When \\
\hline Plan & $\begin{array}{l}\text { Obtain three new computer terminals by explaining a lack of } \\
\text { terminals was contributing to poor completion rates. } \\
\text { Sustain momentum for change. }\end{array}$ & Project team & January 2017 \\
\hline Do & $\begin{array}{l}\text { The terminals are introduced to the department. } \\
\text { Induction training for new doctors is ongoing. }\end{array}$ & $\begin{array}{l}\text { Doctors in the department, } \\
\text { IT department }\end{array}$ & March 2017 \\
\hline Study & $\begin{array}{l}\text { Discharge summary completion rates improved from } \\
<10 \% \text { to } 84 \% \text { in the } 2 \text { months following the introduction. } \\
\text { Historical backlog was cleared in March } 2017 \text {. } \\
\text { Analyse feedback on project so far from coalition. }\end{array}$ & Project team and coalition & April-May 2017 \\
\hline Act & $\begin{array}{l}\text { Aim to provide solutions to problems highlighted by the } \\
\text { coalition. } \\
\text { - Plan to phase out the paper-based system. }\end{array}$ & Project team & May 2017 \\
\hline
\end{tabular}




\section{Step eight}

The final step in Kotter's model is to ensure that the change continues by enforcing it as the new norm. We were able to achieve this by making the department's discharge summary status a routine part of morning handover, highlighting to team members when there were pending discharge summaries.

We also sustained the new 'No discharge summary, no discharge' rule and put up posters to remind team members of this. Everyone within the unit, including the nursing team and the ward manager, helped to reinforce this.

\section{RESULTS}

Our three outcome measures are outlined in the run chart below (figure 2).

The first phase was to clear the backlog of discharge summaries. This work commenced in June 2016 and took 9 months. Following this, in 1 month (March 2017April 2017) we were able to improve the proportion of discharge summaries being completed within 24 hours of patient discharge from $2 \%$ to $84 \%$.

More importantly, we were able to sustain the proportion of discharge summaries being completed within 24 hours of patient discharge at over $80 \%$ for a year postimplementation with just one exception (February 2018, where our 24-hour completion rate was 78\%).

We were able to ensure that the data were as accurate due to the number of patients attending the PAU being routinely recorded (during working hours, by ward clerks, and outside working hours by nursing staff).

Prior to the introduction of the project, there had been an allocated slot on the junior doctor rota where the juniors were tasked with completing discharge summaries during working hours. Following the introduction of the QI project, we were able to remove the discharge summary duty slot from the junior doctor rota and instead deploy an additional junior doctor to clinical duties on the PAU, helping to free up time for patient care.

We reviewed the quality of discharge summaries by printing anonymised versions of discharge summaries and having a group-based assessment of those summaries. The quality of completed summaries was discussed by all grades of doctors in the department, with individuals free to give suggestions for improvements. Learning points from discussion of the anonymised summaries were fed back to team members.

Our discharge summary completion rates slipped over the winter of 2019-2020, especially completion within 24 hours of discharge. Due to very high acuity that winter, we had to review the problem urgently and with our previously successful interventions we were able to reinforce QI steps of the first phase. This ensured we did not go back to the previous state of backlogs prior to the initiation of this project in 2016. In March 2020, our assessment unit was changed to a ward to accommodate COVID-19 demands. Since the start of this QI project, 70\% of our discharge summaries have been completed within 24 hours. This is a testimony to the success of the project and continues to enthuse us to keep up the momentum and make change sustainable.

\section{Lessons and limitations}

While we did conduct occasional spot checks on the quality of the discharge summaries, this was not a regular occurrence during the project. In retrospect, it may have been useful to have made feedback on completed discharge summaries a monthly occurrence to ensure that standards of the discharge summaries remained high.

Additionally, it could have been useful to have sent a questionnaire to local general practitioners at the start of the project and at the end to observe if they had noted any change in the quality of the discharge summaries. No communications were received from general practitioners with regard to poor quality of discharge summaries. The discharge summaries were electronic with mandatory fields, which has been shown previously to improve the satisfaction from general practitioners (see Moy et $\left.a l^{7}\right)$. We therefore believe that improving our discharge summary completion rates did not have a negative impact on their quality. General practitioners were not included in the coalition for change, and we may have benefited from having their input to improve the change process.

We also would have benefited from evaluating junior doctor proficiency in completing electronic discharge summaries before providing the training in induction. To mitigate this, we have now introduced compulsory training in induction that all doctors are familiar with the process. We also now have video tutorials that are now available on the departmental app with other learning repositories.

Sustainability of change needs change in behaviours and the particular challenge to this project is that junior doctors rotate between departments every 4-6 months on average. To ensure change processes withstand and achieve longevity, you need change agents. They become the active proponents of change (Harrington et $a l^{10}$ ) and sustain change. The lead consultant for the project continues to play this role and completion rates have been consistently high (figure 2). Communication, leadership and team approach are the active ingredients in this recipe for sustainability.

Longevity of change is not always guaranteed and this was the challenge we have faced in recent times. The winter surges of 2019 have had an impact on completion rates. We however have managed to reinforce our previously learnt measures to ensure timely action is undertaken to clear the backlogs. This involved consultations with junior doctors and emphasising the importance of timely completion of discharge summaries.

\section{CONCLUSIONS}

This QI project has demonstrated that Kotter's eight-step model for change can be used to improve the timeliness 
of discharge summary completion in a PAU. We believe that our project was additionally successful in that we were able to remove a discharge summary duty slot from the junior doctor rota as we had made sufficient progress in the completion of the generated discharge summaries. This allowed us to free up more time for clinical care. We hope that the example given in this article may help inspire others to try Kotter's eight-step model in their own departments.

The costs involved in the project were minimal apart from the procurement of three new computer terminals. The terminals are also used for clinical practice such as reviewing the results of investigations. This aspect validates the belief that to ensure success of QI projects, we do not always require significant financial expenditure. This can be offset by using the principles of QI that this project has successfully demonstrated.

The project would not have been possible were it not for the time and effort given by the multidisciplinary volunteer coalition. Our future work will involve consolidating this sustained change process and reach our eventual target that $100 \%$ of discharge summaries will be completed within 24 hours of patient discharge.

Twitter Pramodh Vallabhaneni @drpramv

Acknowledgements We would like to thank the hard work of everyone involved in getting the project off the ground and those involved in maintaining the project. This project was authored using the Standards for Quality Improvement Reporting Excellence 2.0 guidelines.

Contributors RTR wrote the first draft of the manuscript. Revised manuscript was cowritten by RTR, IJM and PV. PV conceived and designed the idea for the project, mentored and supervised RTR to write the first draft. PV has overall responsibility for the ongoing quality improvement project.

Funding The authors have not declared a specific grant for this research from any funding agency in the public, commercial or not-for-profit sectors.

Competing interests None declared.
Patient and public involvement Patients and/or the public were not involved in the design, or conduct, or reporting, or dissemination plans of this research.

Patient consent for publication Not required.

Provenance and peer review Not commissioned; externally peer reviewed.

Data availability statement Data are available upon request.

Open access This is an open access article distributed in accordance with the Creative Commons Attribution Non Commercial (CC BY-NC 4.0) license, which permits others to distribute, remix, adapt, build upon this work non-commercially, and license their derivative works on different terms, provided the original work is properly cited, appropriate credit is given, any changes made indicated, and the use is non-commercial. See: http://creativecommons.org/licenses/by-nc/4.0/.

ORCID iDs

Richard Thomas Richmond http://orcid.org/0000-0002-8041-9244

Isobel Joy McFadzean http://orcid.org/0000-0001-9766-2681

Pramodh Vallabhaneni http://orcid.org/0000-0002-4887-8651

\section{REFERENCES}

1 Professional Records Standards Body. EDischarge summary standard v2.1. Available: https://theprsb.org/standards/ edischargesummary/

2 Schwarz CM, Hoffmann M, Schwarz P, et al. A systematic literature review and narrative synthesis on the risks of medical discharge letters for patients' safety. BMC Health Serv Res 2019;19.

3 Were MC, Li X, Kesterson J, et al. Adequacy of hospital discharge summaries in documenting tests with pending results and outpatient follow-up providers. J Gen Intern Med 2009;24:1002-6.

4 Hoyer EH, Odonkor CA, Bhatia SN, et al. Association between days to complete inpatient discharge summaries with all-payer Hospital readmissions in Maryland. $J$ Hosp Med 2016;11:393-400.

5 Arjunan A. A quality improvement project on discharge summaries completion in a nephrology ward. Clin Med 2019;19:73-4.

6 Cook D, Coutinho A, Mathew A. G563(P) Improving the efficient completion of electronic discharge summaries. Arch Dis Child 2015;100:A253-4.

7 Moy NY, Lee SJ, Chan T, et al. Development and sustainability of an inpatient-to-outpatient discharge handoff tool: a quality improvement project. Jt Comm J Qual Patient Saf 2014;40:219-27.

8 Cio Index. Kotter's 8-Step Change model. Available: https://cio-wiki. org/wiki/Kotter\%27s_8-Step_Change_Model

9 Blount S, Carroll S, Harvard Business Review. Overcome resistance to change with two conversations, 2017. Available: hbr.org/2017/05/ overcome-resistance-to-change-with-two-conversations

10 Harrington HJ, Voehl F, Voehl CF. Model for sustainable change PMI White Papers; 2015. 